\title{
Patient Satisfaction with Psychiatric Services: A Survey at a Nigerian Federal Teaching Hospital
}

\section{N. Okwudili K. Obayi ${ }^{1}$, Monday Igwe ${ }^{1}$, Ugochukwu Nnadozie ${ }^{2}$, Christiana Urom-Oti ${ }^{3}$, Festus Asogwa ${ }^{4}$}

\author{
${ }^{1}$ Department of Psychiatry, Ebonyi State University, Abakaliki, Ebonyi State, Nigeria \\ ${ }^{2}$ Department of Surgery \& Nodal Officer, SERVICOM, Federal Teaching Hospital, Abakaliki, Ebonyi State, Nigeria \\ ${ }^{3}$ Department of Nursing Services, Federal Teaching Hospital, Abakaliki, Ebonyi State, Nigeria \\ ${ }^{4}$ Department of Psychology, Federal University, Ndufu-Alike Ikwo, Ebonyi State, Nigeria \\ Email: ^nokobayi@gmail.com, mondayigwe@yahoo.com, ugodozie@yahoo.ca,denisuromoti@yahoo.com, \\ fesasogwa@yahoo.com
}

How to cite this paper: Obayi, N.O.K., Igwe, M., Nnadozie, U., Urom-Oti, C. and Asogwa, F. (2018) Patient Satisfaction with Psychiatric Services: A Survey at a Nigerian Federal Teaching Hospital. Open Journal of Psychiatry, 8, 168-181.

https://doi.org/10.4236/ojpsych.2018.82016

Received: April 3, 2018

Accepted: April 25, 2018

Published: April 28, 2018

Copyright (c) 2018 by authors and Scientific Research Publishing Inc. This work is licensed under the Creative Commons Attribution International License (CC BY 4.0).

http://creativecommons.org/licenses/by/4.0/

(c) (i) Open Access

\begin{abstract}
Background: Patient satisfaction, a measure of the extent to which a patient is content with the health care which he or she receives from his or her health care provider, is an effective means of evaluating the performance of a hospital leading to service improvement and attraction of more patients. In a country whose leadership currently calls for change of attitude of the citizenry, it is pertinent to assess how this change has been accepted in health institutions, especially among the most stigmatized group of patients, by assessing the latter's level of satisfaction with the quality of services provided. Objectives: The study, carried out over a period of six months (1st May to 30th October, 2016), assessed the satisfaction of patients with the quality of care provided at the psychiatric outpatient department of the Federal Teaching Hospital, Abakaliki, Nigeria. Methods: Data were extracted from eligible participants using a sociodemographic/clinical profile questionnaire and the Charleston Psychiatric Outpatient Satisfaction Questionnaire. Results: 422 patients (53.6\% males, $46.4 \%$ females) participated. Their mean age was $32.20 \pm 11.35$ years. Schizophrenia was the commonest diagnosis. The respondents appeared quite satisfied with the quality of services. Satisfaction with the helpfulness of the record officers was topmost in the administrative scale (92.9\%) with satisfaction with the amount of time waited to be seen by doctor, the least (76.3\%) while on the environmental scale, appearance of the doctor's consulting room was most satisfying (93.4\%) and cost of service the least (73.5\%). $90.5 \%$ were satisfied with the overall quality of service provided
\end{abstract}


and $94.8 \%$ indicated willingness to recommend the facility to others. Satisfaction was most affected by self-perceived mental and physical health. Conclusion: Patient satisfaction is a simple way to evaluate hospital services. Continual assessment of patient satisfaction is recommended to enable authorities improve on areas considered less satisfactory while sustaining service areas deemed highly satisfactory.

\section{Keywords}

Patient, Satisfaction, Psychiatric Services

\section{Introduction}

Patient satisfaction is one of the barometers that reflect how well a health care system is working as it is a measure of the extent to which a patient is content with the health care that he or she receives from the provider [1]. It appears to represent patients' attitudes to care or some aspects of care [2] and has, therefore, become increasingly important for healthcare professionals to systematically measure patients' satisfaction with their care. Surveys of patient satisfaction tend to elicit very positive ratings but these ratings are not sensitive to specific problems in the quality of care delivered to patients in various centers. Professionals who deliver health care services should be aware of the needs and wants of their patients as their awareness would significantly affect the patients' satisfaction [3].

Studying patient satisfaction is an effective means of evaluating the performance of a hospital from the view of patients. The information obtained through this type of studies is valuable as that would remove the discrepancies which are distorting the patient satisfaction so as to make the hospital more attractive for the patient. Patients attending each hospital are responsible for spreading the good image of the hospital and therefore satisfaction of patients attending the hospital is equally important for hospital management [4].

SERVICOM is an acronym for Service Compact with all Nigerians-a social contract the Federal Government entered into with all Nigerians on March 21, 2004 to provide basic services to which citizens are entitled to timely, fair, honest, effective, and transparent service [5]. It is machinery for institutionalizing effective public service delivery in Nigeria. SERVICOM golden rule is: serve others as you would like to be served. Its unit is present in all Ministries, Departments and Agencies (MDAs) of Government throughout the Federation and its vision statement in hospitals is usually to ensure delivery of quality healthcare services that are based upon the needs of patients by ensuring the provision of fundamental healthcare services to which each patient is entitled in a timely, fair, honest, effective and transparent manner.

Patient satisfaction in psychiatry is a complex issue with various influencing factors [6]. Nevertheless, delivery of patient-focused care requires that we pro- 
vide care in a particular way, not just sometimes or usually, but always and it must be every patient every time [7].

Satisfaction of psychiatric outpatients has been reported to be different in various clinical and demographic groups and across many domains of satisfaction [6], sometimes varying across diagnostic groups with patients with schizophrenia being least satisfied, compared to patients with major depression who had highest satisfaction with services [6] [8] (although one study did not find any differences between major depressive disorder and schizophrenia in terms of satisfaction [9]) and sometimes, with respect to duration of symptoms [10].

Services provided at public health facilities in Nigeria have been reported to be perceived by members of the public to be very poor [11], a perception held even by health care providers warranting their professional associations periodically demanding that government increases the funding of the health sector [12] [13]. Despite the introduction of SERVICOM over a decade ago, periodic patient satisfaction surveys are not yet routine in our hospitals. Such a survey is very important, especially in mental health services where the belief and attitude of the populace divert majority of the patients away from orthodox to non-orthodox facilities for care.

Only few specific reviews have been published on patient satisfaction with psychiatric services [14] [15] [16]. The Federal Teaching Hospital, Abakaliki, is a young federal government-owned public health institution in South-East Nigeria poised with achieving all her vision and mission statements whose ultimate focus is on patient satisfaction. It is important to evaluate patient satisfaction not only as an outcome in itself but also because low satisfaction can lead to poor compliance with treatment and consequently to below average health outcomes [17] [18] [19]. The findings from this study would help the hospital management and the stakeholders in the Mental Health department identify areas that deserve improvement to ensure optimal service delivery to patients assessing psychiatric services in the institution.

\section{Objectives}

This study aimed at:

1) Determining the level of satisfaction of patients receiving care from the psychiatric outpatient clinic of the Federal Teaching Hospital, Abakaliki; and

2) Exploring the factors associated with satisfaction or dissatisfaction of such patients.

\section{Methodology}

This was a cross-sectional study carried out at the Out-patient unit of the Psychiatry department of the Federal Teaching Hospital, Abakaliki over a six month period, from 1st May to 30th October, 2016. The study population comprised adult out-patients, aged 18 years and above. All eligible and consenting patients seen within the study period were sampled. 


\subsection{Eligibility}

Patients included in the study must have: received care from the department in at least one previous visit; been physically and mentally capable of giving valid responses; literate enough to clearly understand the items on the self-administered questionnaires; and must have presented to the outpatient clinic during normal working hours.

Patients who: were too ill to give valid responses; had cognitive impairment; objected to giving informed consent; or were discharged against medical advice were excluded from the study.

\subsection{Ethical Approval}

Approval for the study was obtained from the Research and Ethics Committee of the Federal Teaching Hospital, Abakaliki, Nigeria (REC Approval Number: 08/04/2016-20/06/2016). Informed consent was obtained from each eligible participant before the participant was enrolled into the study.

\subsection{Instruments for the Study}

These were a self-developed sociodemographic/clinical profile questionnaire that captured the patients' demographical and clinical details, and the Charleston Psychiatric Outpatient Satisfaction Questionnaire/Scale.

The Charleston Psychiatric Outpatient Satisfaction Questionnaire (CPOSS) is a 15-item measure of patients' satisfaction designed for use in outpatient settings. The instrument uses a 5-point Likert-type response format that minimizes positive response bias and optimizes variability and predictive validity. It has been reported to show a high internal reliability as well as convergent validity [20] and has also been found to be valid and reliable for use in a Nigerian outpatient psychiatric clinic service [21].

Items 1 through 14 of the CPOSS are scored using the 5-point scale: $5=\mathrm{Ex}$ cellent, $4=$ Very good, $3=$ Good, $2=$ Fair, and $1=$ Poor. Item 15 is scored using a 4 -point scale as: $4=$ Yes, definitely; $3=$ Yes, probably; $2=$ No, probably not; 1 $=$ No, definitely not.

The scale is scored by summing the scores of all individual items except the anchor items (items 8 and 15). The possible range is 13 to 65 . Some are predictor items, such as overall quality and recommendation intent, and the other items assess administrative and environmental factors unique to the outpatient setting: helpfulness of secretariat, waiting time, amount of information received about the problem, respect for opinions, matching treatment plan with individual needs, helpfulness of services, appearance of waiting room, appearance of office, working hours, location, and parking.

\subsection{Minimum Sample Size Calculation}

The entire population was less than ten thousand $(10,000)$. The final sample estimate (nf) was calculated from the formula 


$$
n f=n / 1+(n / N)
$$

where:

$n f=$ the desired sample size when population is less than 10,000 ;

$n=$ the desired sample size when the population is more than 10,000 ;

$N=$ the estimate of the population size.

Using a standard normal deviate (z) set at 1.96 which corresponds to the $95 \%$ confidence level; $50 \%$ as the proportion in the target population estimated to be satisfied with services (i.e., $p=0.5) ; q$ as the proportion not satisfied $(1.0-\mathrm{p}=$ 0.5 ); and $d$ as the degree of accuracy desired, usually set at 0.05 , the desired sample size when the population is more than $10,000, n$ was calculated from $n=$ $z^{2} p q / d^{2}, \mathrm{n}=(1.96)^{2}(0.50)(0.05) /(0.05)^{2}=384$.

Taking $\mathrm{n}$ as 384 and $\mathrm{N}$ as 2000 (a rough estimate of the population of patients that had received care from the department within the four year period from when the hospital was established to when data were collected, as found from the medical records), $\mathrm{nf}$ was calculated as $\mathrm{nf}=\mathrm{n} / 1+(\mathrm{n} / \mathrm{N})=384 / 1+(384 / 2000)=$ $384 / 1+0.192=384 / 1.192=322$.

To compensate for non-response, with an anticipated response rate of $90 \%$, the sample size selected $\left(\mathrm{n}_{\mathrm{s}}\right)$ was calculated by dividing the calculated sample size $(\mathrm{nf})$ by the anticipated response rate: $\mathrm{n}_{\mathrm{s}}=\mathrm{n} \times(90 \% / 100 \%)=\mathrm{n} / 0.9=322 / 0.9=$ 358. So, a minimum of 358 patients were aimed at for the study.

\subsection{Procedure}

All available consecutive and consenting eligible patients that visited the clinic within the study period were enrolled and interviewed with the study instruments. Each outpatient on arrival to the department was introduced to the study by a non-clinical staff of the department. Consenting eligible patients were told to report back to the non-clinical staff after he/she has finished all he/she has to do on the day in the hospital in relation to his/her ill health. On return, he/she was given the questionnaires for self-administration without any influence from any staff or relative. Thereafter, the non-clinical staff would, from the case note, fill the column for patient's psychiatric diagnosis.

\subsection{Statistical Analysis}

Descriptive statistics was done using the Statistical Package for Social Sciences (SPSS), version 20 and all statistical values were set at $5 \%$ level of significance ( $p$ $<0.05)$.

\section{Results}

\subsection{Sociodemographic Characteristics of Participants}

Out of the 500 enrolled participants, 422 (53.6\% males, $46.4 \%$ females) returned well-filled questionnaires giving a valid response rate of $84.4 \%$. They were aged 18 - 79 years, mean age being $32.20 \pm 11.35$ years; and majority, 258 (61.1\%) fell 
within the age range of 25 - 44. Up to 270 (64.0\%) never married and while as much as $350(82.9 \%)$ had a minimum of Primary education, only 78 (18.5\%) had government job (Figures 1-5).

\subsection{Clinical Profile of the Participants}

Figures 6-7 show the clinical characteristics of the participants. Schizophrenia was the commonest diagnosis. More than $80 \%$ had attended the clinic for a period of over 6 months.

\subsection{Participants' Perception of Their Health Condition}

Table 1 shows the participants' report of how they perceived their mental health, physical health, and general health condition on the day of the interview. $88.1 \%$ perceived their physical health to be good compared to only $12.8 \%$ that perceived

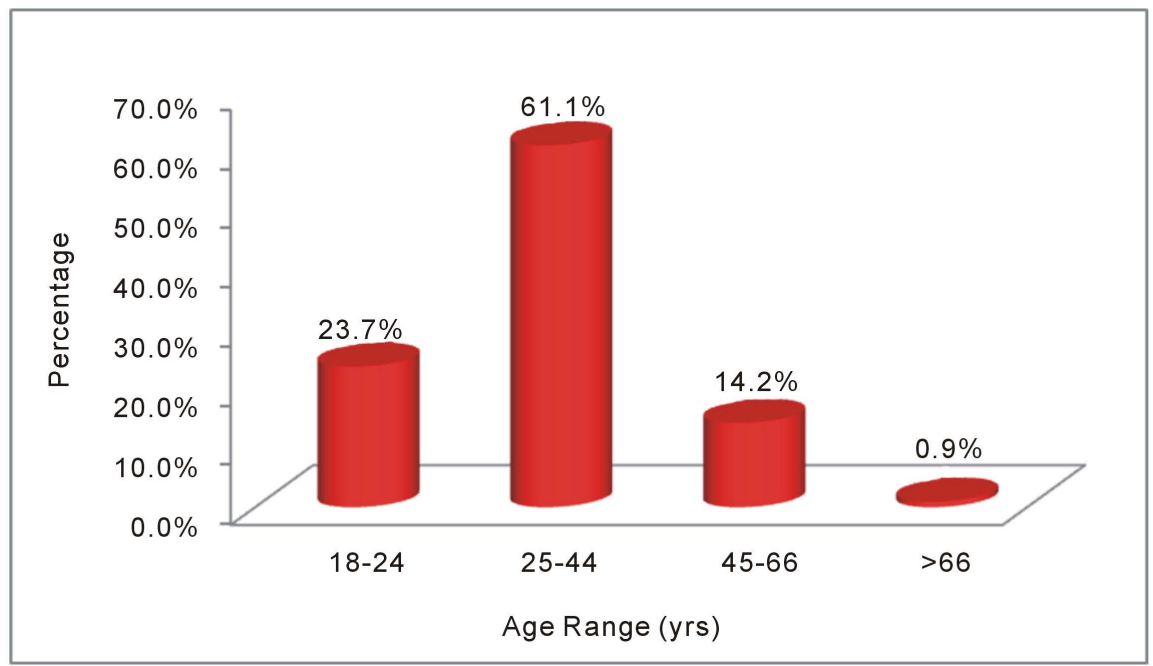

Figure 1. Age range of the participants.

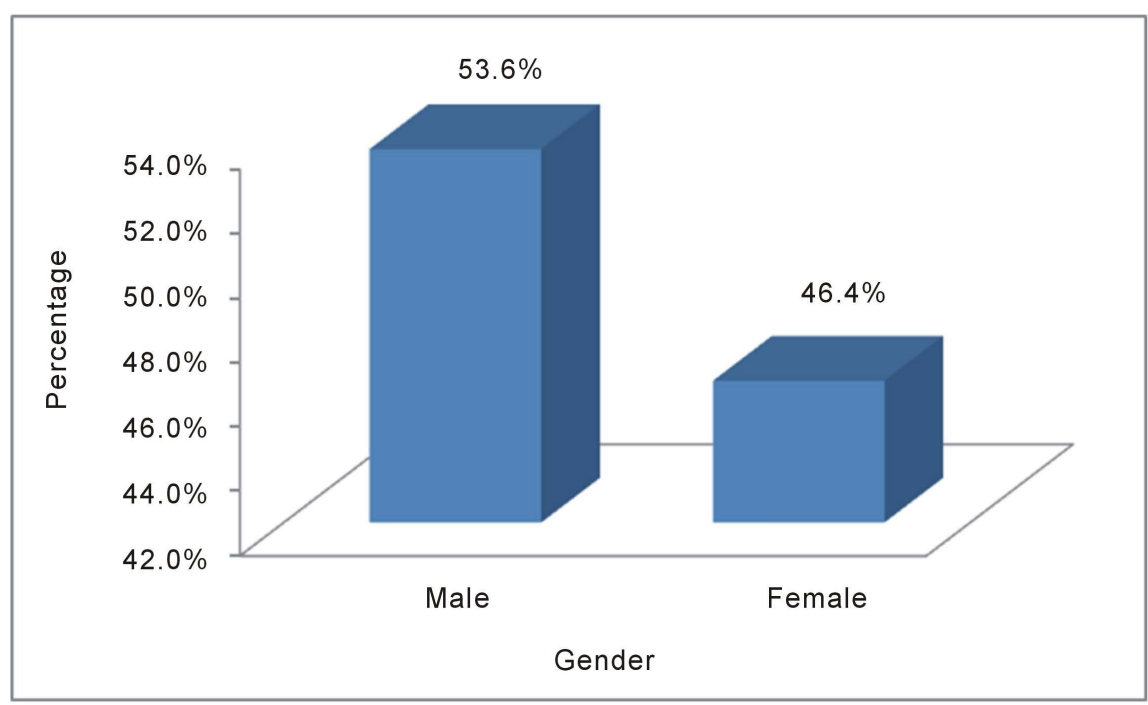

Figure 2. Gender. 


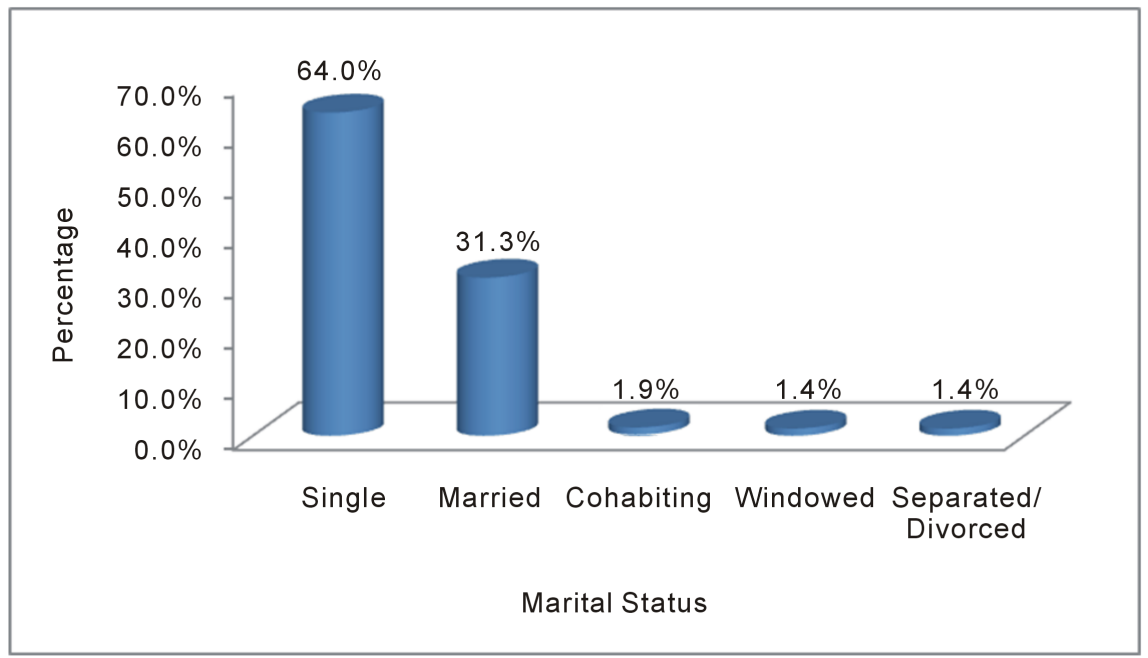

Figure 3. Marital status.

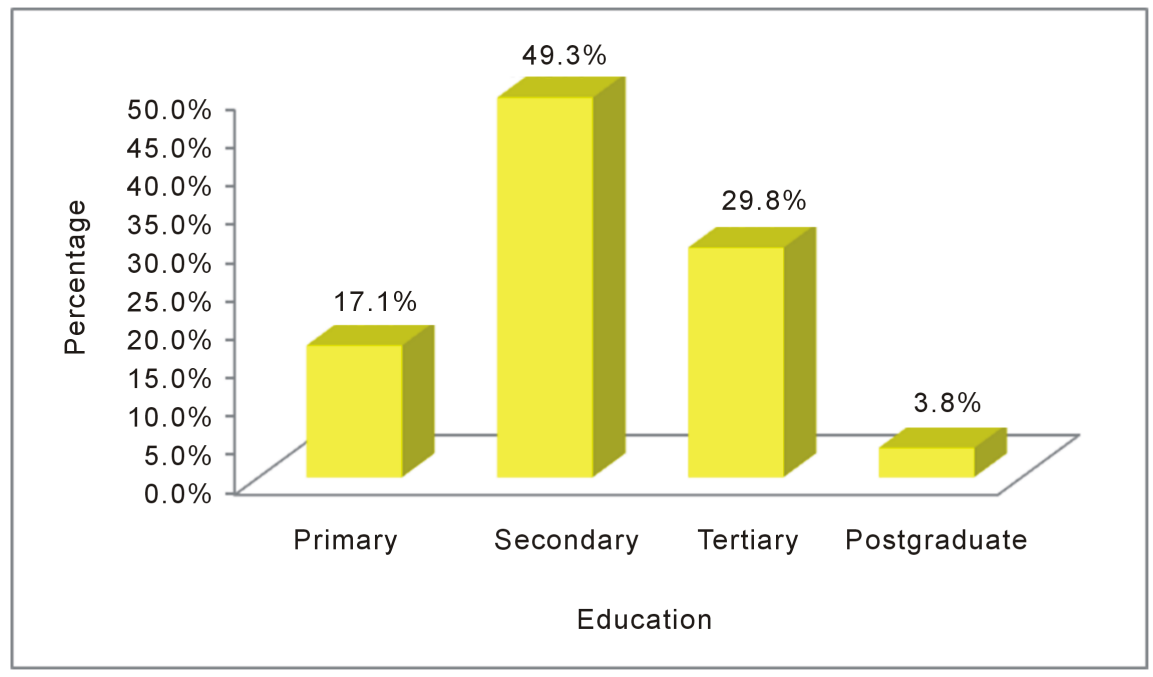

Figure 4. Educational status.

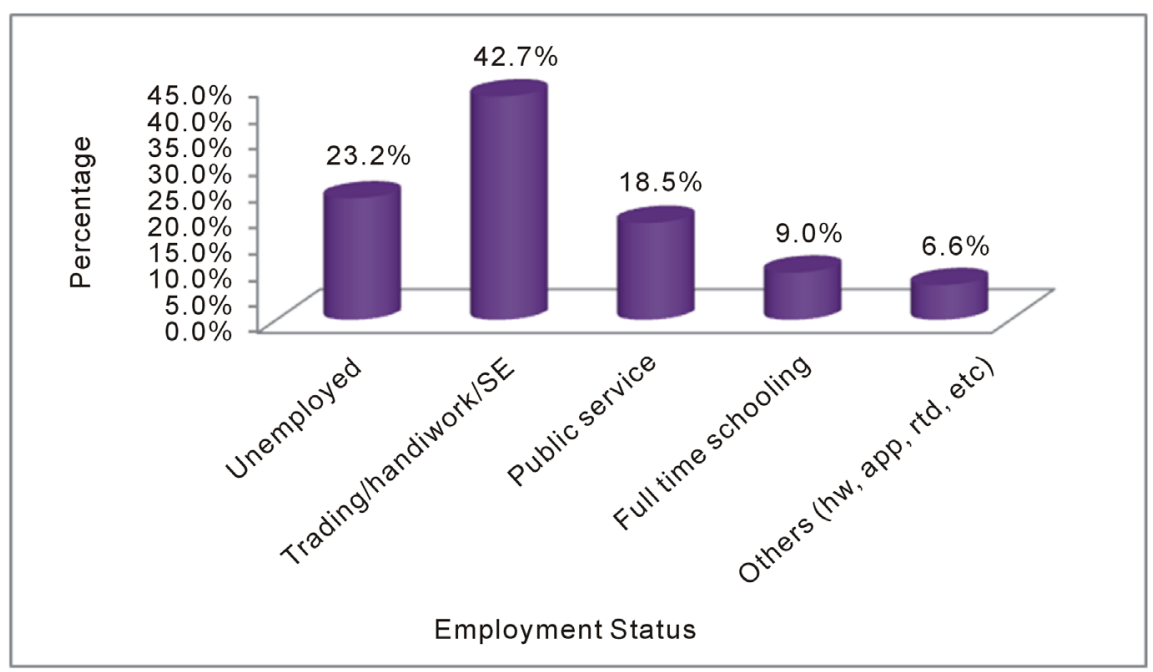

Figure 5. Employment status. 


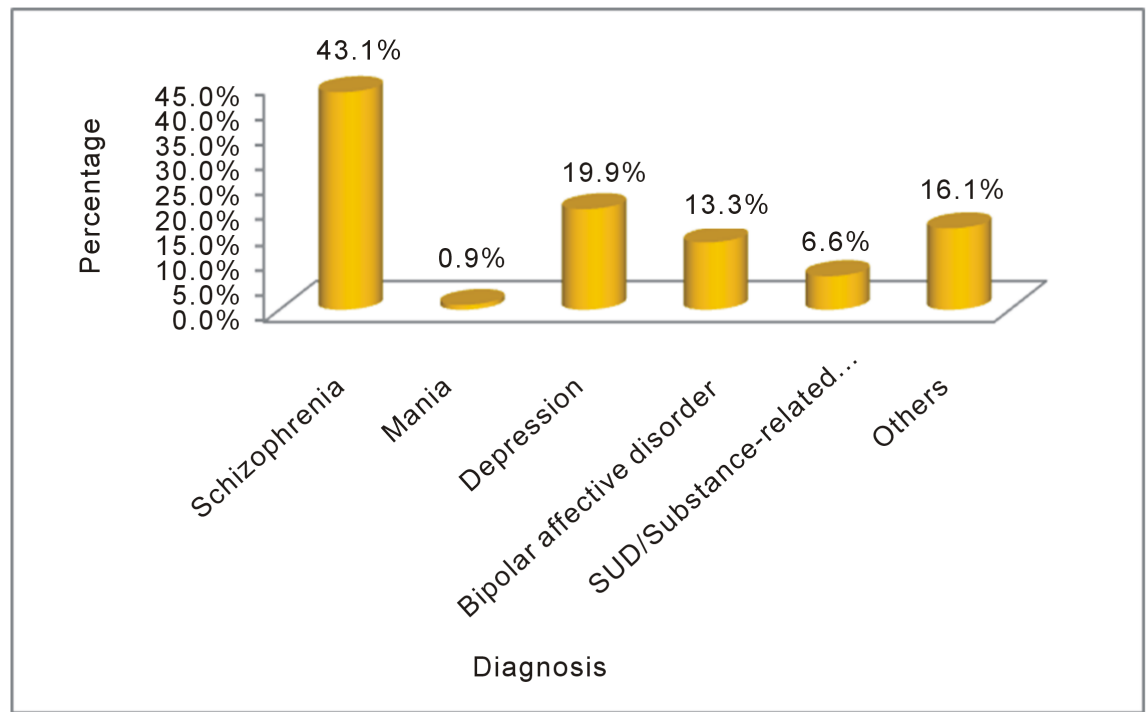

Figure 6. Clinical diagnosis. Note: SUD = substance use disorder; Others = somatization, personality disorders, post-traumatic disorder, etc.

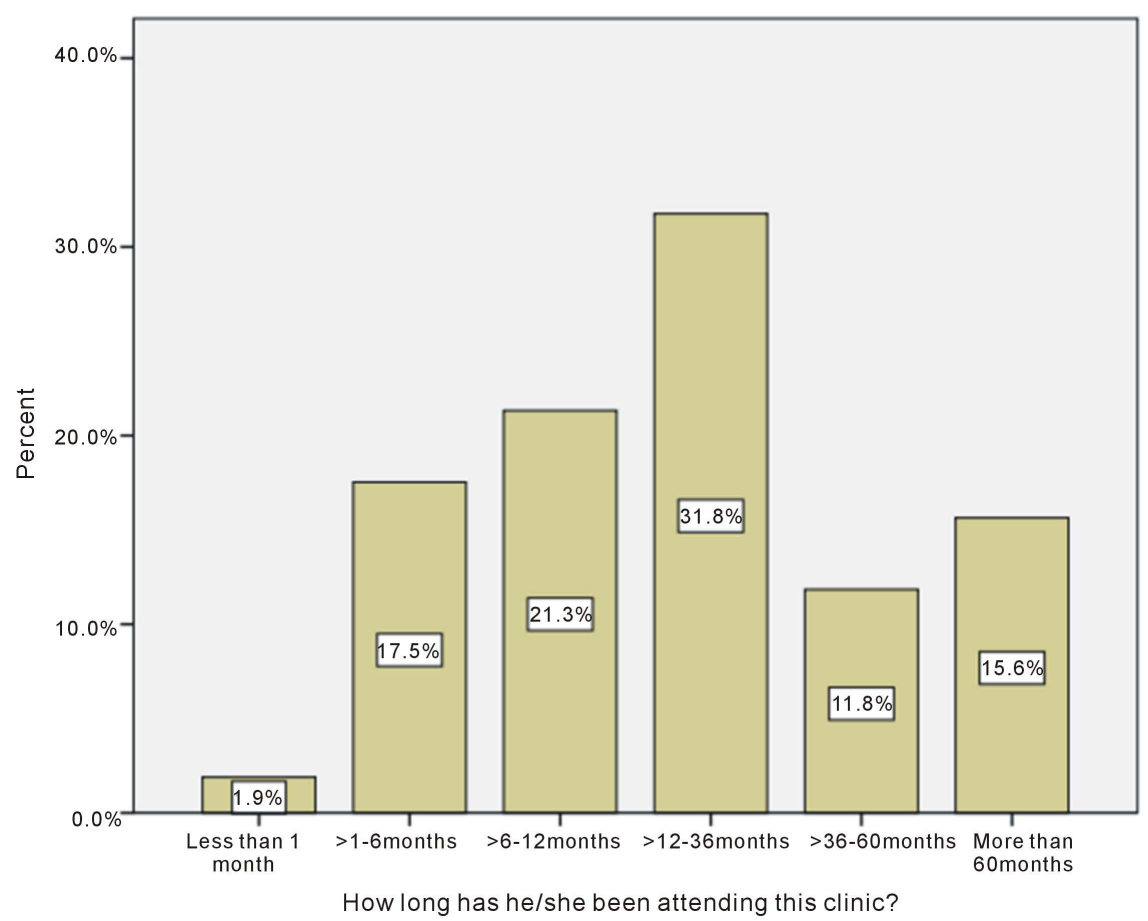

Figure 7. Duration of attendance to the clinic.

their mental health to be good. Three-quarter (75.8\%) considered their general health condition on the day of the interview to be good.

\subsection{Level of Satisfaction}

\subsubsection{Satisfaction with Administrative and Clinical/Treatment Areas}

Table 2 shows the level of participants' satisfaction with administrative and 
Table 1. self-perceived mental health, self-perceived physical health \& general condition $(n=422)$.

\begin{tabular}{|c|c|c|c|c|c|c|}
\hline \multirow[t]{2}{*}{ Option } & \multicolumn{2}{|c|}{$\begin{array}{l}\text { Self-perceived } \\
\text { mental health }\end{array}$} & \multicolumn{2}{|c|}{$\begin{array}{l}\text { Self-perceived } \\
\text { physical health }\end{array}$} & \multicolumn{2}{|c|}{$\begin{array}{c}\text { General health } \\
\text { condition }\end{array}$} \\
\hline & $\mathbf{n}$ & $\%$ & $\mathbf{n}$ & $\%$ & $\mathbf{n}$ & $\%$ \\
\hline Very poor & 176 & 41.7 & 8 & 1.9 & 44 & 10.4 \\
\hline Rather poor & 124 & 29.4 & 12 & 2.8 & 16 & 3.8 \\
\hline Neutral & 68 & 16.1 & 30 & 7.1 & 42 & 10.0 \\
\hline Rather good & 38 & 9.0 & 160 & 37.9 & 108 & 25.6 \\
\hline Very good & 16 & 3.8 & 212 & 50.2 & 212 & 50.2 \\
\hline
\end{tabular}

Table 2. Outpatient satisfaction (with administrative factors) $(\mathrm{n}=422)$.

\begin{tabular}{|c|c|c|c|c|c|c|}
\hline Feedback item & $\begin{array}{l}\text { (a) Poor } \\
\text { n (\%) }\end{array}$ & $\begin{array}{l}\text { (b) Fair } \\
\text { n (\%) }\end{array}$ & $\begin{array}{l}\text { (c) Good } \\
\text { n (\%) }\end{array}$ & $\begin{array}{l}\text { (d) Very } \\
\text { good n (\%) }\end{array}$ & $\begin{array}{l}\text { (e) Excellent } \\
\text { n (\%) }\end{array}$ & $\begin{array}{l}\text { Percentage positives } \\
\qquad(c+d+e)\end{array}$ \\
\hline Helpfulness of the record officers & $10(2.4)$ & $20(4.7)$ & $100(23.7)$ & $122(28.9)$ & $170(40.3)$ & 92.9 \\
\hline $\begin{array}{l}\text { Information provided about } \\
\text { payment for services }\end{array}$ & $4(0.9)$ & $48(11.4)$ & $114(27.0)$ & $152(36.0)$ & $104(24.6)$ & 87.6 \\
\hline $\begin{array}{l}\text { Amount of time waiting to be seen } \\
\text { by doctor }\end{array}$ & $34(8.1)$ & $66(15.6)$ & $96(22.7)$ & $126(29.9)$ & $100(23.7)$ & 76.3 \\
\hline $\begin{array}{l}\text { Amount of information given to } \\
\text { patient about his/her problem. }\end{array}$ & $12(2.8)$ & $50(11.8)$ & $142(33.6)$ & $116(27.5)$ & $102(24.2)$ & 85.1 \\
\hline $\begin{array}{l}\text { Respect shown for patient's } \\
\text { opinion about treatment }\end{array}$ & $12(2.8)$ & $26(6.2)$ & $132(31.3)$ & $156(37.0)$ & $96(22.7)$ & 91.0 \\
\hline $\begin{array}{l}\text { Matching of treatment plan to } \\
\text { patient's individual needs }\end{array}$ & $14(3.3)$ & $32(7.6)$ & $174(41.2)$ & $126(29.9)$ & $76(18.0)$ & 89.1 \\
\hline Helpfulness of the services received & $10(2.4)$ & $30(7.1)$ & $120(28.4)$ & $140(33.2)$ & $122(28.9)$ & 90.5 \\
\hline
\end{tabular}

clinical/treatment areas. High score (showing high level of satisfaction) was recorded in each area assessed.

Satisfaction with the helpfulness of the record officers topped most in the administrative items (92.9\%) while participants were least satisfied with the time waited to be seen by a doctor (76.3\%).

\subsubsection{Satisfaction with Environmental Factors}

Table 3 shows participants' report of their satisfaction with the outpatient environment.

On the environmental scale, the most satisfying factor to the participants was the appearance of the doctor's consulting room (93.4\%) while they were least satisfied with the cost of services (73.5\%).

\subsubsection{Satisfaction with the Overall Quality of Service Provided and Willingness to Recommend the Facility to Others}

Figure 8 and Figure 9 show the participants' satisfaction with the overall quality of service provided and the willingness of the participants to recommend the centre to other people, respectively. $90.5 \%$ were satisfied with the overall quality of service provided and as much as $94.8 \%$ expressed their willingness to recommend the facility to other persons. 
Table 3. Outpatient satisfaction (with environmental factors) $(n=422)$.

\begin{tabular}{|c|c|c|c|c|c|c|}
\hline Feedback item & $\begin{array}{l}\text { (a) Poor } \\
\text { n (\%) }\end{array}$ & $\begin{array}{l}\text { (b) Fair } \\
\text { n (\%) }\end{array}$ & $\begin{array}{l}\text { (c) Good } \\
\text { n (\%) }\end{array}$ & $\begin{array}{l}\text { (d) Very good } \\
\text { n (\%) }\end{array}$ & $\begin{array}{l}\text { (e) Excellent } \\
\text { n (\%) }\end{array}$ & $\begin{array}{l}\text { Percentage positives } \\
\qquad(c+d+e)\end{array}$ \\
\hline Appearance of the waiting room & $4(0.9)$ & $42(10.0)$ & $122(28.9)$ & $136(32.2)$ & $118(28.0)$ & 89.1 \\
\hline $\begin{array}{l}\text { Appearance of the doctor's } \\
\text { consulting room }\end{array}$ & $4(0.9)$ & $24(5.7)$ & $84(19.9)$ & $134(31.8)$ & $176(41.7)$ & 93.4 \\
\hline Office hours (clinic open period) & $4(0.9)$ & $42(10.0)$ & $74(35.1)$ & $59(28.0)$ & $110(26.1)$ & 89.2 \\
\hline $\begin{array}{l}\text { Location of the clinic within the } \\
\text { hospital }\end{array}$ & $12(2.8)$ & $46(10.9)$ & $120(28.4)$ & $114(27.0)$ & $130(30.8)$ & 86.2 \\
\hline $\begin{array}{l}\text { Packing space (space for patient } \\
\text { to pack vehicle) }\end{array}$ & $20(4.7)$ & $64(15.2)$ & $105(24.9)$ & $105(24.9)$ & $76(18.0)^{*}$ & 78.2 \\
\hline $\begin{array}{l}\text { Cost of service (official payment } \\
\text { made for services }\end{array}$ & $18(4.3)$ & $94(7.6)$ & $148(35.1)$ & $88(20.9)$ & $74(17.5)$ & 73.5 \\
\hline
\end{tabular}

${ }^{\star} \mathrm{N} / \mathrm{A}($ not applicable $)=52(12.3 \%)$.

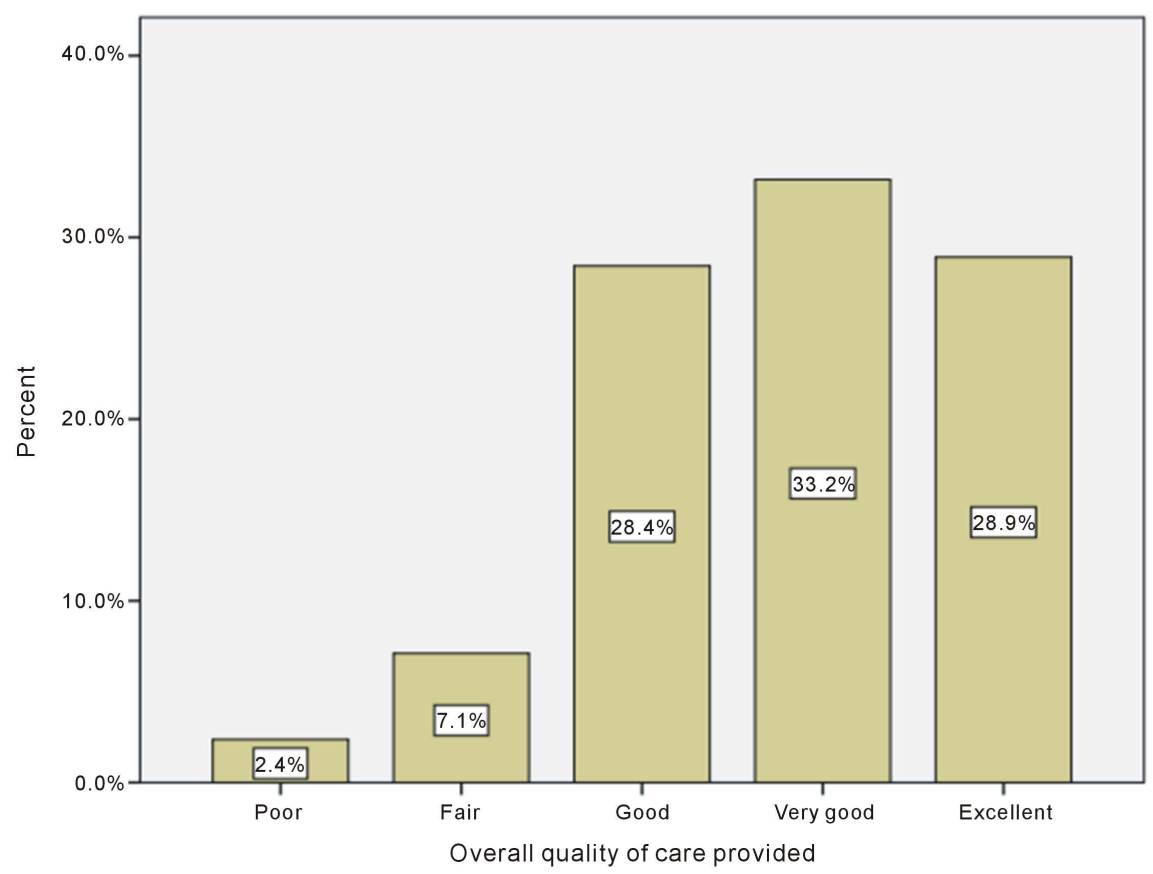

Figure 8. Satisfaction with the overall quality of service provided.

\subsubsection{Factors Associated with Satisfaction with Service}

Various sociodemographic and clinical attributes affected the level of satisfaction in the different areas measured. Age range significantly affected satisfaction with cost of service, with those in the age range of 25 - 44 being more satisfied with the cost $\left(\mathrm{x}^{2}=59.234, \mathrm{p}=0.000\right)$.

Gender (being a female) affected satisfaction with the matching of treatment plan to patient's individual needs $(\mathrm{p}=0.012)$. Being married correlated with better satisfaction with time spent to see a doctor $\left(x^{2}=27.874, p=0.033\right)$, the overall quality of care provided $\left(\mathrm{x}^{2}=27.397, \mathrm{p}=0.037\right)$, and intent to recommend the department to other people $\left(x^{2}=21.167, \mathrm{p}=0.048\right)$.

The more educated the participants, the least were they satisfied with the time 


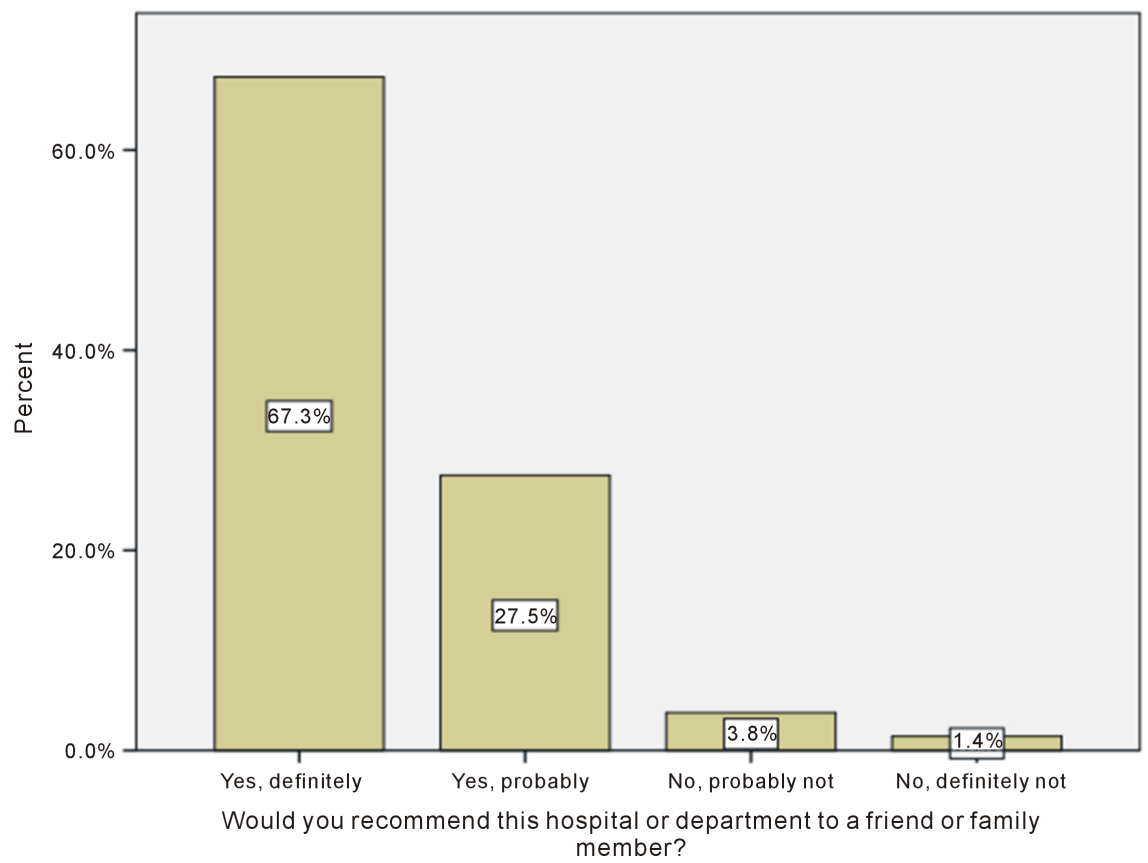

Figure 9. Recommendation intent.

spent to see the doctor $\left(x^{2}=46.502, p=0.015\right)$, and the parking space $\left(x^{2}=\right.$ $50.889, \mathrm{p}=0.005)$.

Having been admitted before was significantly associated with satisfaction with information given about payment $\left(\mathrm{x}^{2}=30.865, \mathrm{p}=0.014\right)$ and matching of treatment plan to patient's individual needs $\left(\mathrm{x}^{2}=28.782, \mathrm{p}=0.012\right)$.

Satisfaction in the different domains was affected mostly by the self-perceived mental and physical health. Satisfaction with the overall quality of care provided was related to: being married $\left(x^{2}=27.397, p=0.037\right)$, one's mental health being perceived positively $\left(\mathrm{x}^{2}=32.982, \mathrm{p}=0.007\right)$, as well as positive perception of one's physical health $\left(\mathrm{x}^{2}=43.931, \mathrm{p}=0.000\right)$.

Job status did not influence satisfaction significantly and no factor was found to be statistically significant with satisfaction with the appearance of the doctor's consulting room. The type of mental disorder (diagnosis) was not found to be significantly related to satisfaction in any of the assessed areas.

\section{Discussion}

Satisfaction of psychiatric outpatients has been reported to be different in various clinical and demographic groups and across many domains of satisfaction [6].

Those who were married were more likely to be satisfied with psychiatric outpatient services compared to those widowed; similar to a recent Ethiopian report [22].

Participants previously hospitalized had a higher level of satisfaction with quality of care compared with those who were never admitted, especially with respect to satisfaction with information given about payment and matching of 
treatment plan to patient's individual needs. Similar finding had been reported [4] [23].

Areas that had higher mean scores on CPOSS such as helpfulness of the records clerk, helpfulness of services received, and so on were in keeping with findings from a very recent local study among people with schizophrenia in Lagos, Nigeria [24].

No significant differences in satisfaction among diagnostic groups is similar to an earlier finding by Olusina et al. [13] in a study in South-West Nigeria as well as a more recent foreign study [9].

The relative less satisfaction with the cost of services could be attributed to some factors such as economic recession and increased hospital bill. At the time of this study (data collection), the country was at the peak of her economic recession, which contributed to the upward review of the bills of the hospital almost shortly before the onset of this study. Recessions are known to cause contractions in economic growth, leading to fiscal crises for governments, compromising their ability to fund medical care and eventually causing employers and hospital managements to alter their service charges to sustain the hospital expenditure and service provision [25]; and patient satisfaction has been reported to be negatively associated with higher levels of hospital medical expenditure [26]. Other major factor responsible for the relative low satisfaction in this area is the fact that almost all the patients sampled have their bills paid directly by themselves or their family members; majority were not under the national health insurance scheme.

The good overall satisfaction with the care provided is similar to a study in a Finnish psychiatric hospital which reported that patients were generally quite satisfied with their care [10].

\section{Strength}

The data collection procedure where a non-clinical staff, that the patient had nothing to gain from in terms of service, was assigned to give out the questionnaires and consent forms reduced bias on a participant's report.

\section{Limitations}

Those who could not read or write and those who presented outside normal working hours (for instance during call hours as emergencies) were excluded.

\section{Conclusion/Recommendation}

Patient satisfaction is a simple way to evaluate hospital services. Continual assessment of patient satisfaction levels is recommended to enable authorities improve on areas considered less satisfactory while sustaining areas of service deemed highly satisfactory. There is a need for every hospital to consider some waivers to patients with mental health problems while reviewing her bill. 


\section{References}

[1] Chun, C.B., Kim, S.Y., Lee, J.Y. and Lee, S.Y. (2009) Republic of Korea: Health System Review. Health System in Transition: World Health Organization on Behalf of the European Observatory on Health Systems and Policies, 11, 1-184.

[2] Webster, S., Gallaher, S., Lopez, V., Brown, P. and Evans, J. (2012) Patients' Satisfaction with Mental Health Nursing Interventions in the Management of Anxiety: Results of a Questionnaire Study. Journal of Nursing Education and Practice, 2, 52-62. https://doi.org/10.5430/jnep.v2n2p52

[3] Rad, N.F., Mat Som, A.P. and Zainuddin, Y. (2010) Service Quality and Patients' Satisfaction in Medical Tourism. Word Applied Sciences Journal, 10, 24-30.

http://citeseerx.ist.psu.edu/viewdoc/download?doi=10.1.1.390.2680\&rep=rep1\&type $=\mathrm{pdf}$

[4] Ghose, S. and Adhish, S.V. (2011) Patient Satisfaction with Medical Services: A Hospital-Based Study. Health and Population Perspectives and Issues, 34, 232-242. http://medind.nic.in/hab/t11/i4/habt11i4p232.pdf

[5] Nigerian Communications Commission. https://www.ncc.gov.ng/

[6] Holikatti, P.C., Kar, N., Mishra, A., Shukla, R. and Swain, S.P. (2012) A Study on Patient Satisfaction with Psychiatric Services. Indian Journal of Psychiatry, 54, 327-332. https://doi.org/10.4103/0019-5545.104817

[7] Prakash, B. (2010) Patient Satisfaction. Journal of Cutaneous and Aesthetic Surgery, 3, 151-155. http://www.jcasonline.com/text.asp?2010/3/3/151/74491 https://doi.org/10.4103/0974-2077.74491

[8] Svensson, B. and Hansson, L. (1994) Patient Satisfaction with Inpatient Psychiatric Care. The Influence of Personality Traits, Diagnosis and Perceived Coercion. Acta Psychiatrica Scandinavica, 90, 379-384. https://doi.org/10.1111/j.1600-0447.1994.tb01610.x

[9] Köhler, S., Unger, T., Hoffmann, S., Steinacher, B. and Fydrich, T. (2015) Patient Satisfaction with Inpatient Psychiatric Treatment and Its Relation to Treatment Outcome in Unipolar Depression and Schizophrenia. International Journal of Psychiatry in Clinical Practice, 19, 119-123. https://doi.org/10.3109/13651501.2014.988272

[10] Kuosmanen, L., Hätönen, H., Jyrkinen, A.R., Katajisto, J. and Välimäki, M. (2006) Patient Satisfaction with Psychiatric Inpatient Care. Journal of Advanced Nursing, 55, 655-663. https://doi.org/10.1111/j.1365-2648.2006.03957.x

[11] Iliyasu, Z., Abubakar, I.S., Abubakar, S., Lawan, U.M. and Gajida, A.U. (2010) Patients' Satisfaction with Services Obtained from Aminu Kano Teaching Hospital, Kano, Northern Nigeria. Nigerian Journal of Clinical Practice, 13, 371-378. http://www.njcponline.com/text.asp?2010/13/4/371/74619

[12] Afolabi, M.O. and Erhun, W.O. (2003) Patients' Response to Waiting Time in an Outpatient Pharmacy in Nigeria. Tropical Journal of Pharmaceutical Research, 2, 207-214. http://www.bioline.org.br/pdf?pr03012

[13] Olusina, A.K., Ohaeri, J.U. and Olatawura, M.O. (2004) Patient and Staff Satisfaction with the Quality of In-Patient Psychiatric Care in a Nigerian General Hospital. Social Psychiatry and Psychiatric Epidemiology, 37, 283-288.

[14] Ruggeri, M. (1994) Patients' and Relatives' Satisfaction with Psychiatric Services: The State of the Art of Its Measurement. Social Psychiatry and Psychiatric Epidemiology, 29, 212-227. https://doi.org/10.1007/BF00796380

[15] Lebow, J.L. (1983) Research Assessing Consumer Satisfaction with Mental Health 
Treatment: A Review of Findings. Evaluation and Program Planning, 6, 211-236. https://doi.org/10.1016/0149-7189(83)90003-4

[16] Boyer, L., Baumstarck-Barrau, K., Cano, N., Zendjidjian, X., Belzeaux, R., Limousin, S., et al. (2009) Assessment of Psychiatric Inpatient Satisfaction: A Systematic Review of Self-Reported Instruments. European Psychiatry, 24, 540-549. https://doi.org/10.1016/j.eurpsy.2009.05.011

[17] Harris, L.E., Luft, F.C., Rudy, D.W., et al. (1995) Correlates of Health Care Satisfaction in Inner-City Patients with Hypertension and Chronic Renal Insufficiency. Social Science \& Medicine, 41, 1639-1645. https://doi.org/10.1016/0277-9536(95)00073-G

[18] Keith, R.A. (1998) Patient Satisfaction and Rehabilitation Services. Archives of Physical Medicine and Rehabilitation, 79, 1122-1128.

https://www.ncbi.nlm.nih.gov/pubmed/9749695 https://doi.org/10.1016/S0003-9993(98)90182-4

[19] Albrecht, G. and Hoogstraten, J. (1998) Satisfaction as a Determinant of Compliance. Community Dentistry and Oral Epidemiology, 26, 139-146.

https://www.ncbi.nlm.nih.gov/pubmed/9645408 https://doi.org/10.1111/j.1600-0528.1998.tb01940.x

[20] Pellegrin, K.L., Stuart, G.W., Maree, B., Frueh, B.C. and Ballenger, J.C. (2001) A Brief Scale for Assessing Patients' Satisfaction with Care in Outpatient Psychiatric Services. Psychiatric Services, 52, 816-819. https://doi.org/10.1176/appi.ps.52.6.816

[21] Ukpong, D.I., Mosaku, S.K., Aloba, O. and Mapayi, B. (2008) Reliability and Validity of a Satisfaction Scale in a Nigerian Psychiatric Out-Patient Clinic. Nigerian Journal of Psychiatry, 6, 31-36. https://doi.org/10.4314/njpsyc.v6i1.39908

[22] Yimer, S., Yohannis, Z., Getinet, W., Mekonen, W.F., Belete, H., Menberu, M., Getnet, A. and Belete, A. (2016) Satisfaction and Associated Factors of Outpatient Psychiatric Service Consumers in Ethiopia. Patient Preference and Adherence, 10, 1847-1852.

[23] Zendjidjian, X., Auquier, P., Lançon, C., Loundou, A., Parola, N., Faugere, M. and Boyer, L. (2014) Determinants of Patient Satisfaction with Hospital Health Care in Psychiatry: Results Based on the SATISPSY-22 Questionnaire. Patient Preference and Adherence, 8, 1457-1464.

[24] Afe, T.O., Bello-Mojeed, M. and Ogunsemi, O. (2016) Perception of Service Satisfaction and Quality of Life of Patients Living with Schizophrenia in Lagos, Nigeria. Journal of Neurosciences in Rural Practice, 7, 216-222. https://doi.org/10.4103/0976-3147.178652

[25] Goldsmith, J. (2016) Recessions: A Predictable Financial Risk for Hospitals. Hospitals and Health Networks.

https://www.hhnmag.com/articles/7819-recessions-a-predictable-financial-risk-forhospitals

[26] Shan, L., Li, Y., Ding, D., Wu, Q., Liu, C., Jiao, M., et al. (2016) Patient Satisfaction with Hospital Inpatient Care: Effects of Trust, Medical Insurance and Perceived Quality of Care. PLOS ONE, 11, e0164366.

https://doi.org/10.1371/journal.pone.0164366 